REGULAR ARTICLE

\title{
TECHNICAL EFFICIENCY AND ITS DETERMINANTS IN DAIRY CATTLE
}

\author{
Monika Michaličková*1, Zuzana Krupová ${ }^{1}$, Emil Krupa ${ }^{2}$
}

Address: Monika Michaličková,

${ }^{1}$ Animal Production Research Centre Nitra, Institute for Animal Breeding and Product

Quality, Hlohovecká 2, 95141 Nitra - Lužianky, Slovak Republic

${ }^{2}$ Institute of Animal Science, Genetics and Breeding of Farm Animals, PO Box 1, 10401

Prague, Czech Republic

*Corresponding author: michalickova@cvzv.sk

\begin{abstract}
The objective of this study was to analyse the technical efficiency (TE) of the milk production on totally 83 cattle herds (database of APRC Nitra) in the period 2006-2010 and to synthesise impact of the main inputs (costs) on the TE value. A nonparametric approach Data Envelopment Analysis with the input-oriented variable return to scale model was used to evaluate the TE value. Average value of TE in the analysed period was 0.96, i.e. evaluated herds reached $96 \%$ of technical efficiency in milk production on average. For these, reduction of inputs by $4 \%$ is recommended to reach the efficiency at the given level of milk yield. Value of individual inputs: total feed costs, material costs, labour costs, repair and service, depreciation, other direct costs and overhead costs, should be reduced by 3.7, 10.0, 3.3, 15.8, 2.1, 2.9 and $8.5 \%$ respectively, while maintaining the same level of output. It is possible to state that the analysed farms are inefficient in utilization of inputs for the given level of output. The TE value was statistically significantly influenced by the feed costs only. The negative influence of this factor indicates inefficient utilization of feeds (balance of feeding ration, losses of storage, reciprocal substitution of feeds) or inefficient utilization of its production potential in relation to the given output level.
\end{abstract}

Key words: DEA, technical efficiency, determinants, milk

JEL classifications: C14, C35, C61, Q12 


\section{INTRODUCTION}

Rational relation between inputs and outputs along with utilization of given sources, aimed to the maximum gratification of needs, are the main requirements for efficient production. Effectiveness of the expended inputs (technical efficiency) is an important item in animal production. Decrease of technical efficiency leads to rising of unit costs and to reduction of production value. Moreover, in the economics of animal production it is necessary to consider the biological efficiency of breeding as well. It is taken as the ability to utilize the material inputs (expressed in costs) into marketable product in common production conditions. DEA methodology is used in many of papers dealing with analyses of efficiency in dairy cattle sector (Boudný et al., 2011; Demircan et al., 2010). The objective of this study was to analyse the technical efficiency of milk production in dairy cattle farms in Slovakia for the period 2006 to 2010, and to synthesize the influence of the main inputs to the level of technical efficiency.

\section{MATERIAL AND METHODS}

\section{Data and descriptive statistics}

Technical efficiency of milk production and its determinants were evaluated for the years 2006 to 2010. In total, data from 83 cattle herds were analysed, recorded in the database of the Animal Production research Centre (APRC) Nitra. The base production and economic (cost and revenues) data of dairy cows, detailed consultations with management of the herds, and results of milk recording in cattle were used in the analyses. The studied farms were chosen randomly to represent all of the production regions in Slovakia (average elevation of the farm's seat was $491 \mathrm{~m}$ above sea level), all breeds of dairy cattle and their crosses farmed in Slovakia. On average, 322 heads of dairy cows, $88 \%$ fertility, $6 \%$ death loss of cows, and $15.99 \mathrm{~kg}$ of milk yield per feeding day with milk marketability ${ }^{1}$ of $93 \%$ was achieved in analysed herds. Age at first calving of cows was 963 days, calving interval ${ }^{2}$ reached 439 days and average production life of cows was 3.14 lactations. Total profit to cost ratio ${ }^{3}$ ranged from $-21 \%$ to $5 \%$ (without direct subsidies ${ }^{4}$ ), or from $-12 \%$ to $8 \%$ (with direct subsidies).

\footnotetext{
1 (sold milk/produced milk)*100

2 time between two calvings of a cow in days

${ }^{3}$ (profit or loss/total costs)*100

4 payment per livestock unit (2007-2010), additional national direct payment per dairy cow and support per dairy cow - help in milk crisis (2010)
} 
Higher changes in profit to cost ratio were found only in 2009 to 2010, when milk price dropped down and prices of inputs (costs) increased. Milk surplus on markets in the time of the crisis was based on the weakened purchasing power of consumers. On the other hand, decreased value of milk price opened the area for farmers to find reserves in the value and in the structure of costs (fixed and feed costs mainly) in relation to the real intensity of production. Farmers solved this situation through decreased number of cows in the herd, reduced amount of purchased feeds and their substitution by own feeds. But this substitution was not effective as the average milk yield per cow slowly decreased in this period.

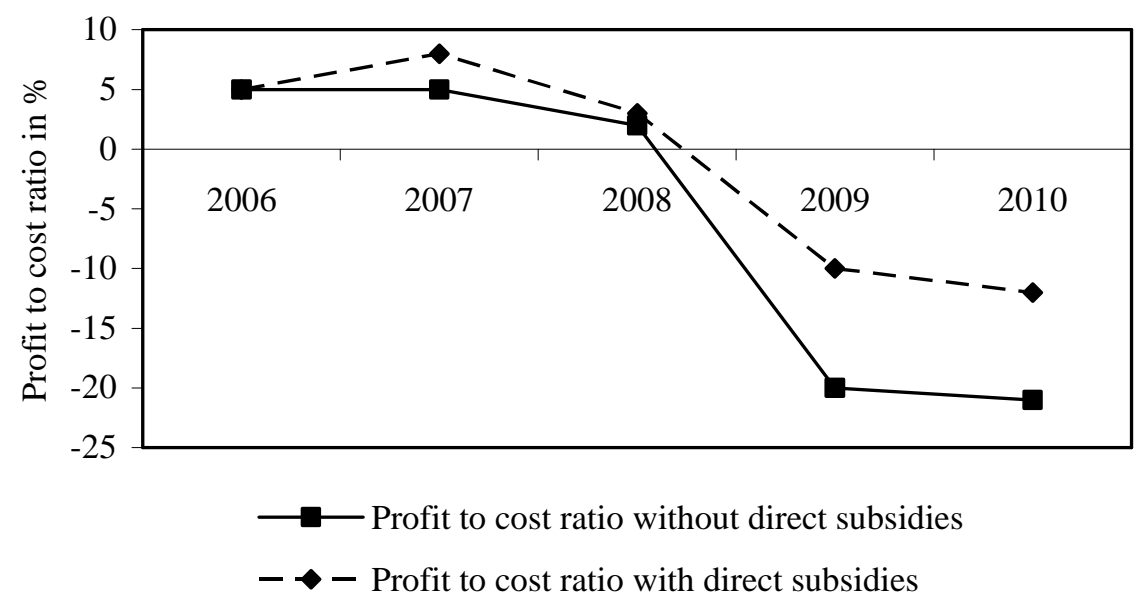

Figure 1 Profit to cost ratio in dairy cattle farms in years 2006-2010 (\%)

\section{Technical efficiency}

The non-parametric approach DEA, known as Data Envelopment Analysis with input orientation of the model and variable returns to scale (VRS) was used to quantify the technical efficiency. Using the DEA approach, the condition of relative homogeneity was fulfilled, that means that the evaluated farms used similar inputs and technologies to produce similar outputs. The principle of the method was to compare the individual production units (herds), where the maximal limit of efficiency was created by the unit with the highest value of the input effectiveness. Technical efficiency of the individual production unit measured as efficiency score was expressed in relation to this unit as the relative parameter (nondimensional number). It numerically expressed the distance of the given production unit to the efficiency limit. It is assumed that all production units are lying either on the efficiency limit or under it. The coefficient (score) of technical efficiency ranged from 0 to 1. 
More information about the DEA model is available in Charnes et al. (1978) and Banker et al. (1984). Two basic types of envelopment surfaces can be estimated. First is referred to a Constant Return to Scale surface (CRS) and the second to a Variable Return to Scale (VRS) surface (Charnes et al., 1978). When assuming CRS, total technical efficiency is estimated. Total technical efficiency can be further decomposed into the pure technical efficiency (PTE) and scale efficiency. To calculate PTE, production technology is assumed to display the VRS. Scale efficiency is then the residual between the total and PTE. In the case of VRS is valid, the production unit will be efficient although the growth of revenues is lower or higher in relation to the growth of outputs.

For TE under the VRS, the input oriented model of Banker et al. (1984) was applied as it is supposed, that Slovak farms have not been profiled on the optimal production range. If the TE score is:

- equal 1 indicating that the farm lies on the VRS envelopment surface. The farm thus is technically efficient and cannot reduce its observed combination of inputs without reducing its output;

- less than 1 indicates the farm is technically inefficient. This score can be interpreted as the amount by which the farm can reduce its combination of inputs while still producing the same level of output (1-TE).

Formal notation of DEA model is as follows (Banker et al. 1984):

$\min _{\theta, \lambda, s^{+}, s^{-}} z_{i}=\theta-\varepsilon * 1 s^{+}-\varepsilon * 1 ' s$

subject to

$Y \lambda-s^{+}=Y_{i}$

$\theta X_{i}-X \lambda-s^{-}=0$

$\lambda, s^{+}, s^{-} \geq 0$

And additional scale constraints:

a) $\lambda \geq 0$ in CRS program

b) $\boldsymbol{1}^{\prime} \lambda=1$ in VRS program

c) $\boldsymbol{1}^{\prime} \lambda \leq 1$ in NIRS (non-increasing returns to scale) program

where $\theta$ is a measure of technical efficiency (TE), $\mathrm{Y}_{\mathrm{i}}=\left(\mathrm{y}_{1}, \ldots, \mathrm{y}_{\mathrm{m}}\right)$ is an output vector, $X_{i}=\left(x_{1}, \ldots, x_{k}\right)$ is an input vector, $Y$ is $(n \times m)$ matrix of $m$ outputs of the each of $n$ investigated farms and $X$ is $(n \times k)$ matrix of $k$ inputs of the each of $n$ investigated farms and 
$\mathbf{1}^{\prime}=(1, \ldots, 1)$ is a row vector. In the program (1) $s^{+}$is $m \times 1$ vector of slacks which represent output deficits, $s^{-}$is $k \times 1$ vector of slacks representing excess of inputs and $\mathbf{1}^{\prime}=(1, \ldots, 1)$ is a row sum-up vector of the appropriate dimension $(1 \times m$, or $1 \times k)$. Index $i$ shows the evaluated farm and $\lambda$ is a vector of $\mathrm{k}$ intensities that characterise each farm. A farm is efficient only if following constraints are satisfied:

1. $\theta *=1$

2. All slack variables $s^{+}$and $s^{-}$equals zero.

To calculate TE, one output (milk production in $€$ ) and 6 inputs represented the production inputs (feed costs, material costs, labour costs, depreciations, other direct costs and overhead costs, all in $€$ ) given in non-negative value was used (table 1).

The influence of variables (feeds, material costs, wages, repairs and service, depreciations, other direct costs and overheads) on the TE values was quantified by regression analysis at the level of significance $95 \%$. Characteristics of individual components applied in the regression model are given in table 1 . The following regression equation was used to examine the relationship between the cost attributes and the TE of milk production:

$T E j=\beta_{0}+\beta_{1} x_{j 1}+\beta_{2} x_{j 2}+\beta_{3} x_{j 3}+\beta_{4} x_{j 4}+\beta_{5} x_{j 5}+\beta_{6} x_{j 6+} \beta_{7} x_{7}+\varepsilon_{j}$

where $T E j$ is the value of technical efficiency of $\mathrm{j}$-th farm (unit), $\beta_{0}$ is intercept, $\beta_{1}$ to $\beta_{7}$ are regression coefficients for individual independent variables, $\mathrm{x}_{\mathrm{j} 1}$ are feed costs, $x_{j 2}$ are material costs, $x_{j 3}$ are labour costs, $x_{j 4}$ are repair and service costs, $x_{j 5}$ are depreciations, $x_{j 6}$ are other direct costs, $x_{j}$ are overheads and $\varepsilon_{j}$ is residua.

\section{RESULTS AND DISCUSSION}

\section{Technical efficiency}

Average value of TE of milk production was 0.96 over the analysed period 2006-2010. It means that the evaluated farms achieved $96 \%$ technical efficiency in this period on average. They should reduce the inputs by $4 \%$ to reach the efficiency at the given level of milk yield. On average, $16 \%$ of the analysed herds reached the TE value higher than 0.9 and $68 \%$ of the herds were fully effective in milk production during the evaluated period. Base statistical characteristics of the TE according to individual years are given in table 2 . These values could 
be positively influenced by the lower number of respondents (production units). The reason is that DEA creates the limit of efficiency according to the best respondent compared the others. In addition, the homogeneity of production, lower influence of natural and climatic conditions and lower determination by human work is typical for animal production. Therefore, the TE of milk production calculated for these systems is generally higher than the TE of farms oriented to mixed or to plant production (Boudný et al., 2011; Fandel, 2003).

Table 1 Base characteristic of the inputs and outputs in dairy cattle farms in 2006-2010

\begin{tabular}{|c|c|c|c|c|c|c|}
\hline "Variable (in $€$ per feeding day) & Statistics variable & 2006 & 2007 & 2008 & 2009 & 2010 \\
\hline \multirow[t]{4}{*}{ Feed costs } & Mean & $\overline{1.81}$ & 2.29 & 2.85 & 2.34 & 2.36 \\
\hline & Standard deviation & 0.40 & 0.74 & 0.73 & 0.42 & 2.36 \\
\hline & Minimum & 1.27 & 1.44 & 1.70 & 1.45 & 1.62 \\
\hline & Maximum & 2.81 & 3.60 & 4.13 & 2.81 & 3.09 \\
\hline \multirow[t]{4}{*}{ Material costs } & Mean & 0.20 & 0.22 & 0.22 & 0.17 & 0.19 \\
\hline & Standard deviation & 0.09 & 0.10 & 0.09 & 0.13 & 0.19 \\
\hline & Minimum & 0.04 & 0.04 & 0.11 & 0.00 & 0.05 \\
\hline & Maximum & 0.36 & 0.36 & 0.34 & 0.51 & 0.39 \\
\hline \multirow[t]{4}{*}{ Labour costs } & Mean & 0.95 & 0.57 & 0.36 & 0.44 & 0.48 \\
\hline & Standard deviation & 0.09 & 0.41 & 0.15 & 0.20 & 0.48 \\
\hline & Minimum & 0.72 & 0.22 & 0.10 & 0.16 & 0.16 \\
\hline & Maximum & 0.68 & 1.62 & 0.64 & 0.71 & 0.89 \\
\hline \multirow[t]{4}{*}{ Repairs and service } & Mean & 0.08 & 0.12 & 0.07 & 0.07 & 0.11 \\
\hline & Standard deviation & 0.04 & 0.09 & 0.03 & 0.05 & 0.11 \\
\hline & Minimum & 0.00 & 0.00 & 0.02 & 0.01 & 0.01 \\
\hline & Maximum & 0.17 & 0.31 & 0.11 & 0.18 & 0.34 \\
\hline \multirow[t]{4}{*}{ Depreciation } & Mean & 0.91 & 0.96 & 0.98 & 0.97 & 0.99 \\
\hline & Standard deviation & 0.33 & 0.35 & 0.20 & 0.19 & 0.99 \\
\hline & Minimum & 0.27 & 0.40 & 0.44 & 0.52 & 0.57 \\
\hline & Maximum & 1.31 & 1.96 & 1.24 & 1.27 & 1.53 \\
\hline \multirow{4}{*}{ Other direct costs } & Mean & 0.90 & 1.26 & 1.08 & 1.10 & 1.15 \\
\hline & Standard deviation & 0.21 & 0.68 & 0.27 & 0.29 & 1.15 \\
\hline & Minimum & 0.49 & 0.50 & 0.67 & 0.59 & 0.63 \\
\hline & Maximum & 1.44 & 3.25 & 1.60 & 1.72 & 2.14 \\
\hline \multirow[t]{4}{*}{ Overhead costs } & Mean & 0.39 & 2.21 & 0.49 & 0.51 & 0.49 \\
\hline & Standard deviation & 0.29 & 0.80 & 0.41 & 0.40 & 0.49 \\
\hline & Minimum & 0.03 & 1.29 & 0.02 & 0.04 & 0.05 \\
\hline & Maximum & 1.24 & 4.10 & 1.48 & 1.12 & 1.15 \\
\hline \multirow[t]{4}{*}{ Production of milk* } & Mean & 0.31 & 0.35 & 0.34 & 0.34 & 0.36 \\
\hline & Standard deviation & 0.02 & 0.06 & 0.02 & 0.06 & 0.36 \\
\hline & Minimum & 0.28 & 0.30 & 0.32 & 0.28 & 0.29 \\
\hline & Maximum & 0.36 & 0.52 & 0.41 & 0.53 & 0.44 \\
\hline
\end{tabular}

$*($ in $€$ per kg of milk)

To improve the value of TE in dairy cattle farmers in evaluated period, the value of inputs: total feed costs, material costs, labour costs, repair and service, depreciation, other direct costs and overhead costs, should be non-radially reduced by 3.7, 10.0, 3.3, 15.8, 2.1, 2.9 
and $8.5 \%$ respectively, while maintaining the same level of milk yield. For example, concentrated feeds, forage feeds, labour and capital can be reduced by 15.3, 24.6, 26.5 and 13.6\%, respectively (Demircan, et al., 2010). Potential reductions in individual inputs (cost items) to improve the $\mathrm{TE}$ of milk production in cattle farms during the studied period are summarised in table 3 .

Table 2 Summary statistics of technical efficiency (TE) in milk production over the evaluated period

\begin{tabular}{lccccr}
\hline \hline & 2006 & 2007 & 2008 & 2009 & 2010 \\
\hline \hline Mean & 0.95 & 0.94 & 0.98 & 0.98 & 0.96 \\
Standard deviation & 0.09 & 0.10 & 0.06 & 0.05 & 0.08 \\
Minimum & 0.72 & 0.66 & 0.84 & 0.84 & 0.75 \\
Average inefficiency & 0.05 & 0.06 & 0.02 & 0.02 & 0.04 \\
Share of farms over 0.9 TE & $17 \%$ & $15 \%$ & $15 \%$ & $13 \%$ & $18 \%$ \\
Share of farms fully efficient & $67 \%$ & $60 \%$ & $69 \%$ & $79 \%$ & $65 \%$ \\
\hline \hline
\end{tabular}

Table 3 Potential change of inputs for improvement of technical efficiency (\%)

\begin{tabular}{lrrrrrr}
\hline \hline Input & 2006 & 2007 & 2008 & 2009 & 2010 & Mean \\
\hline \hline Total feed costs & 5.0 & 4.9 & 0 & 0 & 1.2 & 3.7 \\
Material costs & 1.5 & 4.2 & 14.7 & 18.6 & 11.0 & 10.0 \\
Labour costs & 2.0 & 2.8 & 5.1 & 1.8 & 5.0 & 3.3 \\
Repairs and service & 7.8 & 51.3 & 5.9 & 6.8 & 7.5 & 15.8 \\
Depreciation & 1.4 & 3.4 & 0.1 & 1.3 & 4.0 & 2.1 \\
Other direct costs & 2.1 & 6.9 & 1.7 & 0.8 & 2.8 & 2.9 \\
Overhead costs & 3.1 & 5.4 & 21.7 & 4.7 & 7.5 & 8.5 \\
\hline \hline
\end{tabular}

\section{Determinants of $T E$}

On the basis of literature, number of cows in herd, major inputs in dairy cattle (feed, labour and capital), hectares of the cultivated land, hectares of fodder crops, contact with the extension, the membership in cooperatives and organization and education of employees and experience of farmers can be included into the most evaluated determinants of the production efficiency in cattle farms (Bailey et al., 1989; Bravo-Ureta and Rieger, 1991; Mbaga et al., 2002; Binami et al., 2004). This study was mainly focused on the prices of inevitable production inputs expressed by individual cost items. Regression parameters expressing the relationship between the costs attribute and the TE of milk production (equation 7) are given in table 4. 
The price of pastures and meadows used for grazing of cattle is included into the feed costs along with own and purchased feeds and litters (Krupová et al., 2012). Feed costs represented about 30-35\% on the total costs of milk production (Michaličková et al., 2013).

Table 4 Determinants of the technical efficiency of milk production in cattle herds

\begin{tabular}{llrr}
\hline \hline Variable & Parameter & Coefficient & p-value \\
\hline \hline Constant & $\beta_{0}$ & 1.1397 & $<.0001$ \\
Total feed costs & $\beta_{1}$ & -0.0369 & 0.0084 \\
Material costs & $\beta_{2}$ & -0.1735 & 0.0533 \\
Labour costs & $\beta_{3}$ & 0.0061 & 0.8893 \\
Repairs and services & $\beta_{4}$ & -0.2416 & 0.0561 \\
Depreciation & $\beta_{5}$ & -0.0518 & 0.0899 \\
Other direct costs & $\beta_{6}$ & 0.0163 & 0.5369 \\
Overhead costs & $\beta_{7}$ & -0.0116 & 0.3178 \\
\hline \hline
\end{tabular}

The negative relation to the technical efficiency was found at the level of significance $95 \%$ in the given regression model for feed costs. Increase the value of feed costs by $1 €$ decreased the value of TE in milk production by $3.7 \%$. The negative influence of this factor indicates the inefficient utilization of feeds (balance of feed mixture, losses at storage, substitution of feeds) or inefficient utilization of their production potential in relation to the given output level (milk yield).

Material costs, repairs and services, depreciation and overhead costs were negatively related to the TE of milk production, but they were statistically insignificant. On the other hand, labour costs were positively related to the TE value, but they were statistically insignificant as well. Nevertheless, positive relationship indicates on possibilities to improve TE through employees participating in the higher utilisation of inputs and on the economic efficiency of the milk production (motivation system). Other direct costs were positively related to the TE of milk production but no statistically significance was observed as well.

\section{CONCLUSION}

The objective of this paper was to analyse the technical efficiency of the milk production in 83 cattle herds (database of APRC Nitra) for the period 2006-2010 as well as to synthesize the influence of basic production inputs (costs) on the level of technical efficiency using a nonparametric approach Data Envelopment Analysis and regression analysis. The analysed farms achieved $96 \%$ of the technical efficiency on average. They should reduce their inputs by $4 \%$ to reach the efficiency at the given level of milk yield. Values of TE founded in the analyses could be positively influenced by the lower number of respondents (production 
units). In addition, homogeneity of production typical for animal production, lower influence of natural and climatic conditions, as well as lower determination by human labour played the role. Therefore the TE calculated for these systems is generally higher than the TE of farms oriented to mixed or to plant production. For dairy cattle farmers, value of inputs: total feed costs, material costs, labour costs, repair and service, depreciation, other direct costs and overhead costs, can be reduced by $3.7,10.0,3.3,15.8,2.1,2.9$ and $8.5 \%$ respectively, while maintaining the same level of milk yield in the evaluated period. The TE value was statistically significantly influenced only by the level of feed costs. Negative value of this factor indicates the inefficient utilization of feeds (balance of feed mixture, losses of storage, substitution of individual feeds) or inefficient utilization of its production potential in relation to the given output level (milk yield). Impact of material costs, labour costs, depreciations, repairs and services, other direct costs and overheads on the TE value was statistically nonsignificant in the given regression model. For sustainability of ruminants in Slovakia it is recommended to improve the utilization of inputs (mainly feeds) along with higher utilisation of production and reproduction potential of cattle herds. Moreover, individual costs (especially overhead costs) should be charged in a reasonable amount and calculated only for the animal category they belong to.

Acknowledgments: This paper is devoted to the memory of Ing. Jozef Daňo, CSc. in recognition of respect and thanks for his life-work. Thanks are due to the reviewers for helpful comments and to dairy cattle farmers in Slovakia for providing economic and production data.

The research was supported by project "CEGEZ" No 26220120042 and "MLIEKO" (Operational Programme Research and Development funded from the European Regional Development Fund) and RÚ0910503/10/16/1000003 of the Slovak Republic and by the Project MZE 0002701404 of the Czech Republic.

\section{REFERENCES}

BAILEY, D. V. - BISWAS, B. - KUMBHAKAR, S. C. 1989. An analysis of technical allocative and scale inefficiency: The Case of Ecuadorian Dairy Farms. In Western Journal of Agricultural Economics, ISSN 0162-1912, vol. 14, 1989, no. 1, 30-37. 
BANKER, R. D. - CHARNES, A., COOPER, W. W. 1984. Some Models for Estimating Technical and Scale Inefficiences in Data Envelopment Analysis. In Management Dairy farm efficiency Science, ISSN 0025-1909, vol. 30, 1984, no. 9, 1078-1092.

BINAM, J. N. - TONYE, N. W. - NYAMBI, G. - AKOA, M. 2004. Factors affecting the technical efficiency among smallholder farmers in the slash and burn agriculture zone of Cameroon. In Food Policy, ISSN 0306-9192, vol. 35, no. 5, 531-545.

BOUDNÝ, J. - JANOTOVÁ. B. - MEDONOS. T. 2011. Analýza efektivních a méně efektivních podniků (The Analysis of efficient and less efficient companies). Prague: IAEI, 2011. $32 \mathrm{p}$.

BRAVO-URETA, B. E. - RIEGER, L. 1991. Dairy farm efficiency measurement using stochastic frontiers and neoclassical duality. In American Journal of Agricultural Economics, ISSN 1467-8276, vol. 73, 1991, no. 2, 421-428.

DEMIRCAN, V. - BINICI, T. - ZULAUF, C. R. 2010. Assessing pure technical efficiency of dairy farms in Turkey. In Agricultural Economics, ISSN 0139-570X, vol. 56, 2010, no. 3, $141-148$.

FANDEL, P. 2003. Technical and scale efficiency of corporate farms in Slovakia. In Agricultural Economics, ISSN 0139-570X, vol. 49, 2003, no. 8, 375 - 383.

CHARNES, A. - COOPER, W. W. - RHODES, E. 1978. Measuring the efficiency of decision making units. In European Journal of Operational Research, ISSN 0377-2217, vol. 2,1978 , no. $2,429-444$.

KRUPOVÁ, Z. - MICHALIČKOVÁ, M. - KRUPA, E. 2012. Review of methodologies for costs calculating of ruminants in Slovakia. In Journal of Central European Agriculture, ISSN 1332-9049, vol. 13, 2012, no. 3, 426-445.

MBAGA, D. M. - ROMAIN, R. - LARUE, B. - LEBEL, L. 2003. Assessing technical efficiency of Québec dairy farms. In Canadian Journal of Agriculture Economic, ISSN 1744-7976, vol. 51, 2003, no. 1, 121 - 137.

MICHALIČKOVÁ, M. - KRUPOVÁ, Z. - KRUPA, E. 2013. Costs efficiency and its determinants in dairy cattle. In Slovak Journal of Animal Science. ISSN 1337-9984, submitted. 